\title{
The impact of maternal child- and self-oriented pain-related injustice appraisals upon maternal attention to child pain, attention to anger, and pain-attending behavior
}

British Journal of Pain 2021, Vol. 0(0) 1-14 (c) The Author(s) 2021

\section{(c) (i)}

Article reuse guidelines: sagepub.com/journals-permissions DOI: $10.1177 / 20494637211057092$ journals.sagepub.com/home/bjp (S)SAGE

\section{Fleur Baert ${ }^{1} \oplus$, Dimitri Van Ryckeghem ${ }^{1,2,3}$, Alvaro Sanchez-Lopez ${ }^{4}$, Megan M Miller $^{5} \odot$, Adam T Hirsh ${ }^{5}$, Zina Trost $^{6}$ and Tine Vervoort ${ }^{1}$}

\begin{abstract}
Objectives: The current study investigated the role of maternal child- and self-oriented injustice appraisals about child pain in understanding maternal attention for child pain and adult anger cues and painattending behavior.

Methods: Forty-four children underwent a painful cold pressor task (CPT) while their mother observed. Eye tracking was used to measure maternal attention to child pain and adult anger cues. Initial attention allocation and attentional maintenance were indexed by probability of first fixation and gaze duration, respectively. Maternal pain-attending behaviors toward the child were videotaped and coded after CPT completion. Mothers also rated the intensity of pain and anger cues used in the free-viewing tasks. All analyses controlled for maternal catastrophizing about child pain.

Results: Neither child-oriented nor self-oriented injustice was associated with maternal attentional bias toward child pain. Regarding attention toward self-relevant anger cues, differential associations were observed for self- and child-oriented injustice appraisals, with maternal self-oriented injustice being associated with a greater probability of first fixating on anger and with higher anger ratings, whereas maternal child-oriented injustice was associated with enhanced attentional maintenance toward anger. Neither type of maternal injustice appraisals was associated with maternal pain-attending behavior, which was only associated with maternal catastrophizing.

Conclusions: The current study sheds light on potential differential mechanisms through which maternal self- vs. child-oriented injustice appraisals may exert their impact on parent and child pain-related outcomes. Theoretical implications and future directions are discussed.
\end{abstract}

\section{Keywords}

pediatric pain, injustice, anger, attention, parents

\footnotetext{
${ }^{1}$ Department of Experimental-Clinical and Health Psychology, Ghent University, Ghent, Belgium

${ }^{2}$ Department of Clinical Psychological Science, Maastricht University, Maastricht, Netherlands

${ }^{3}$ Department of Behavioural and Cognitive Sciences, University of Luxembourg, Esch-sur-Alzette, Luxembourg

${ }^{4}$ Department of Personality, Evaluation and Psychological Treatment, Complutense University of Madrid, Madrid, Spain

${ }^{5}$ Department of Psychology, Indiana University - Purdue University Indianapolis, Indianapolis, IN, USA

${ }^{6}$ Department of Physical Medicine and Rehabilitation, Virginia Commonwealth University, Richmond, VA, USA
}

\section{Corresponding author:}

Fleur Baert, Department of Experimental-Clinical and Health Psychology, Faculty of Psychology and Educational Science, Ghent University, Henri Dunantlaan 2, 9000 Ghent, Belgium.

Email: fleur.baertaugent.be 


\section{Introduction}

In pediatric chronic pain, parental factors have long been shown to have a crucial impact upon child pain experience. Specifically, parental appraisal processesthe way a parent appraises their child's pain-are associated with relevant child outcomes. Research amongst healthy children and children suffering from chronic pain increasingly highlights the role of parental injustice appraisals about child pain in understanding deleterious child pain-related outcomes such as heightened disability and impaired health-related functioning. ${ }^{1-5}$ Perceived injustice is conceptualized as an appraisal cognition comprising elements of severity and irreparability of loss due to pain, blame and a sense of unfairness. ${ }^{6}$ Recent work further suggests that parents may hold injustice appraisals related to their child (i.e., child-oriented appraisals; "it's unfair for my child") as well as to themselves as parents (i.e., selforiented appraisals; "it's unfair for me"), with both appraisal types exerting a unique impact on child outcomes. $^{5}$

Research on injustice appraisals about (adult) personal pain has identified a number of potential mechanisms through which injustice appraisals may exert their impact. First, anger has been proposed as a key emotional mechanism in chronic pain and injustice $^{7-10}$ Anger is also observed to mediate the relationship between perceived injustice and pain intensity among adults living with chronic pain. ${ }^{11}$ Second, pain-related and anger-related attentional biases may also be particularly relevant to injustice appraisals. Indeed, a recent study among adults living with chronic pain did indicate an association between injustice appraisals and attentional bias toward pain. ${ }^{12}$ While heightened pain-related attentional bias did not mediate the relationship between injustice appraisals and pain-related outcomes, findings demonstrated that participants reporting higher levels of perceived injustice rated facial pain stimuli as more angry, suggesting that biased attention to personal anger cues (rather than pain) may be key. Indeed, Liossi et al. ${ }^{13}$ found attentional bias toward angry faces to be associated with anger, an emotional state consistently found to be associated with chronic pain and perceptions of injustice. $^{7-10}$

A third potential mechanism involves parental caregiving behavior. This notion draws upon previous findings indicating a close relationship between parental pain-related injustice and catastrophic appraisals about child pain with the latter type of appraisals prioritizing protective behaviors to control the child's pain. ${ }^{14-19}$ Such pain controlling behaviors are also referred to as pain attending behaviors which typically direct the child's attention toward pain and have a detrimental impact on child outcomes. ${ }^{20}$ Further, several studies indicate that adults with high painrelated injustice appraisals display more protective pain behaviors and fear of movement, ${ }^{15,21,22}$ supporting the potential relevance of injustice appraisals in parental protective or pain attending responses.

To date, no research has focused on the above mentioned mechanisms in explaining the impact of parental injustice appraisals about child pain. As such, the current study sought to examine the role of parental injustice appraisals in explaining parental anger, attentional processing of child pain and caregiver anger cues, and parental pain-attending behavior in response to child pain. We hypothesized that higher levels of parental injustice appraisals would be uniquely associated with (1) higher self-reported anger, (2) greater attentional bias to child pain and self-relevant anger cues, and (3) more parental pain-attending behavior. Furthermore, in line with the findings of Baert et al., ${ }^{5}$ we further explored the potentially differential impact of parental self- versus other-oriented injustice appraisals.

\section{Method}

\section{Participants}

The present study sample was recruited within a larger study protocol that had the following aims: (1) examine the role of child pain-related injustice appraisals on pain behavior in response to a painful cold pressor task (CPT1), (2) examine the role of parental pain-related injustice appraisals in parental anger, attention bias toward pain, attention bias toward anger, and (non-) pain-attending behavior in response to their child performing a second cold pressor task (CPT2), and (3) examine the role of mother and child attachment in attentional processing of environmental cues. During recruitment, the study was introduced as a study into how children experience pain and parental responses to child pain. The current manuscript reports findings on the second aim of this protocol, focusing solely on parental pain-related injustice appraisals. Procedures involved in the first and third aims of the study occurred independently from the methodology described below and are thus not expected to interfere with current results. Participants (i.e., parent-child dyads) were recruited through the distribution of flyers in local community settings (e.g., youth movements and sports clubs), via social media channels (e.g., Facebook and Twitter), and through the departmental research website. For this study, only mothers were recruited as this was an inclusion criterion for the third aim of the 
study. Therefore, from this point forward, we will refer to participants as "mothers." Dyads interested in participation $(N=64)$ were contacted by phone and screened for study eligibility. The main inclusion criterion for mothers was serving as the child's primary caregiver. Exclusion criteria for children were a diagnosed developmental disorder and the presence of a chronic pain condition (i.e., pain that has persisted over a period of 3 months). As children would be asked to perform a cold pressor test, an additional set of exclusion criteria was applied. Children were excluded when cold water immersion was contraindicated, for instance, in case of an existing cardiovascular disorder or open wounds or sores on the hand. ${ }^{23,24}$ Of the 64 mother-child dyads who expressed interest to participate in the current study, six dyads were excluded after screening, 10 dyads indicated no longer being interested in participating, and 4 dyads withdrew due to time constraints. The final sample consisted of 44 healthy school children (23 boys and 20 girls) aged 8 to $16\left(M_{\mathrm{age}}=10.95, S D=2.06\right)$ and their mothers $\left(M_{\mathrm{age}}=40.90, S D=5.47\right.$, range $27-51$ years $)$. One child declined to participate in the pain-related part of the study and was therefore not included in the final sample for analysis. All mother-child dyads were of Belgian nationality. Most mothers were either married or cohabiting $(N=36,83.7 \%)$. Mothers generally reported being in excellent or good health $(M=1.20, S D=0.98)$. The vast majority of mothers $(N=38,88.4 \%)$ had obtained education beyond the age of 18 years. Dyads received a financial compensation of $€ 25$ for participation. Ethical approval for this study was obtained from the Ethics Committee of the Faculty of Psychology and Educational Sciences, Ghent University (Belgium).

\section{Cold pressor task apparatus}

Experimental pain was induced via the cold pressor task (CPT), which is appropriate for use with children. ${ }^{23,24}$ and provides an analog for various types of naturally occurring pain. Children were asked to perform this task twice. However, the first CPT pertained to the first aim of the larger study, which will not be discussed in this manuscript. Both CPTs were conducted about 30 min apart and mothers only observed the second CPT. First, children were asked to immerse their left hand (the right hand was immersed in the first CPT) in a tank with room temperature $\left( \pm 21^{\circ} \mathrm{C}\right)$ water for 2 minutes to standardize skin temperature prior to cold pressor immersion. ${ }^{24}$ Children were then instructed to immerse the same hand into the cold water tank up to just above their wrist. They were instructed to keep their hand immersed up to tolerance level (i.e., "Keep your hand immersed until you really can't stand it anymore") or until instructed to stop by the researcher (after an uninformed ceiling of $4 \mathrm{~min}$ ). During this immersion, mothers observed their child from an adjacent room on a monitor streaming video from the child's testing room. The child was unaware of the mother observing them. The cold pressor apparatus was set to maintain a water temperature of $10^{\circ} \mathrm{C}\left( \pm 1^{\circ} \mathrm{C}\right)$ and was continuously circulated by a pump to prevent the water around the immersed hand from warming up.

\section{Stimulus materials}

Facial pain stimuli. The stimulus set used for the freeviewing task assessing parent attention to child pain (see below) consisted of 40 grey-scaled images of 10 different children ( 5 males and 5 females; age range 9-16 years) displaying four levels of pain expression: no pain expression (NPE), low pain expression (LPE), moderate pain expression (MPE), and high pain expression (HPE). These stimuli were drawn from an existing set of video tapes of children performing the cold pressor task in a previous study by Vervoort and colleagues ${ }^{25}$ and were successfully used in previous studies by the same authors. ${ }^{26-28}$ All pictures were reliably coded in terms of occurrence and intensity of facial pain display using the Child Facial Coding System (CFCS) ${ }^{29}$ with picture pain ratings increasing significantly with increasing levels of facial pain expressiveness. ${ }^{30}$ With this image set, three types of pairings were compiled, resulting in 30 slides. Each slide consisted of two images of the same child displaying a no pain neutral facial expression paired with either a low, moderate or high pain expression. Image pairs were compiled twice such that the neutral expression appeared equally as often on the left and right side of the screen. The inclusion of four levels of pain expression allowed us to explore whether the relationship between parental pain-related injustice appraisals and parental attention bias varies with varying levels of child expression of pain.

Facial anger stimuli. The stimulus set used for the freeviewing task assessing parental attention toward adult anger consisted of 16 images of eight adult faces (4 males and 4 females) either displaying no anger expression (NAE) or an angry facial expression (AE). These stimuli have been drawn from one-second video clips of simulated facial anger expressions previously created and validated by Simon and colleagues using the Facial Action Coding System (FACS). ${ }^{31}$ Eight actors were videotaped while enacting neutral facial expressions (NAE) and a simulated facial expression of anger (AE). Using these pictures, a set of eight study slides was created, where each slide consisted of two 
images of the same adult displaying a neutral facial expression combined with a simulated anger expression. Pairs were compiled twice such that the neutral expression appeared equally as often on the left and right side.

To determine the validity of the anger expression levels (i.e., NAE and AE), 11 independent judges ( 3 males and 8 females) rated the stimuli on anger intensity on a numerical rating scale ranging from 0 ("Not angry/neutral") to 10 ("A lot of anger"). A paired samples $t$-test indicated a significant difference in judges' ratings between neutral and anger stimuli $(t(7)=-3.25, p<0.05)$, showing that judges rated the anger stimuli $(M=4.60 ; S D=1.50)$ as significantly more angry than the neutral stimuli $(M=2.66 ; \mathrm{SD}=1.15)$.

\section{Eye movement measurement}

Mothers' eye movements were tracked with a $300 \mathrm{~Hz}$ Tobii (TX300) table-mounted eye tracker (Tobii Technology AB-Danderyd, Sweden); a system consisting of a 17 inch computer screen with a camera and infrared LED optics embedded beneath it. The system records eye movements based on corneal reflection caused by an infrared light source, using binocular dark pupil tracking methodology. Participants were seated comfortably $60 \mathrm{~cm}$ away from the center of the screen and asked to move as little as possible. Participants completed a calibration task, focusing on nine sequentially appearing red dots presented in random placement on the screen. The free-viewing tasks commenced only after adequate calibration was reached, as determined by the Tobii calibration system. In case of inadequate calibration, this procedure was repeated until satisfactory.

\section{Free-viewing (eye-tracking) tasks}

Mothers completed two free-viewing tasks: one task assessed attention bias toward pain in children (pain faces task), while the second task assessed attention bias toward adult anger cues (anger faces task). The order of presentation of both tasks was counterbalanced across participants. In order to increase the personal relevance of the stimuli, specific instructions were given before the start of each task. For the pain faces task, mothers received the instruction that they would be presented with images of children performing the same CPT their child would be performing. For the anger faces task, mothers received the instruction that they would be viewing images of parents that were taken while watching their own child perform the CPT.
Within each of the free-viewing tasks, each trial began with a $500 \mathrm{~ms}$ presentation of a white fixation cross, on which participants were instructed to focus first. After the initial $500 \mathrm{~ms}$, the eye-tracker was programmed to wait until detecting a visual fixation of $200 \mathrm{~ms}$ on the cross area. After participants made that visual fixation in the center of the screen, a slide with a pair of images (facial pain or anger stimuli vs. a neutral stimulus, depending on the task) was presented against a grey background for $3000 \mathrm{~ms}$, during which participants were free to explore the slide. After a $200 \mathrm{~ms}$ inter-trial interval (grey screen), the next trial began with the presentation of the fixation cross. The pain and anger free-viewing tasks consisted of 120 and 64 trials, respectively, in which each stimulus (i.e., pain or anger vs. neutral) was shown equiprobably at each location. Pictures were $16 \mathrm{~cm}$ high and $10 \mathrm{~cm}$ wide and were separated by $4.4 \mathrm{~cm}$ from the edge of the slide (see Figure 1). Slides were presented in random order.

\section{Picture ratings of facial pain and anger stimuli}

Upon study completion, mothers were asked to rate each child and adult image used in the eye tracking tasks for pain and anger intensity, respectively. Ratings were made on an 11-point scale ranging from 0 ("No pain/ anger at all") to 10 ("A lot of pain/anger"). Images from each stimulus set were presented in a PowerPoint presentation on a computer screen. The order of presentation of these image sets (i.e., pain and anger) was counterbalanced between participants. Average ratings were calculated for each level of pain (NPE, LPE, MPE, and $\mathrm{HPE}$ ) and anger (NAE and $\mathrm{AE}$ ), resulting in four mean pain ratings and two mean anger ratings ranging from 0 to 10 .

\section{Measures}

Self-report measures. Maternal appraisals of child and self-oriented pain-related injustice were assessed by means of a situation-specific item drawn from the Injustice Experience Questionnaire (IEQ). ${ }^{6}$ The item was adjusted to measure maternal momentary child- and selforiented injustice appraisals regarding their child's pain (i.e., following cold pressor participation). This approach is in line with previous studies where situationspecific versions of the Pain Catastrophizing Scale (Parent and Child version) were created consisting of one or two items for each subscale. ${ }^{28,32}$ The IEQ comprises two subscales; "severity/irreparability of loss" and "blame and unfairness." As the specific pain situation at hand (i.e., the cold pressor task) does not involve any type of loss, this subscale was not deemed relevant and hence not included. One core item (i.e., 


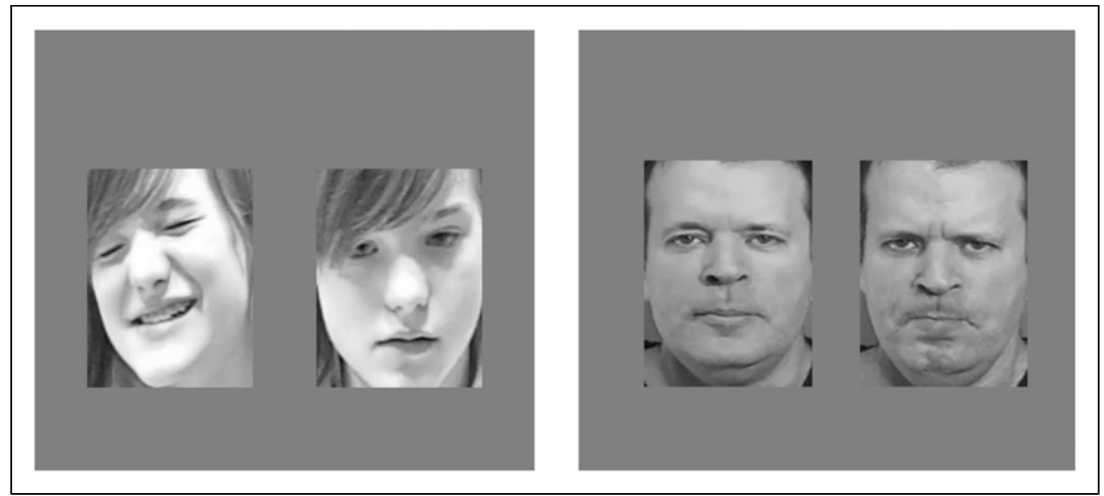

Figure 1. Example of a trial used in the pain free viewing task (left) with the painful cue on the left and the neutral image on the right, as well as the anger free viewing task (right) with the neutral image on the left and the angry image on the right.

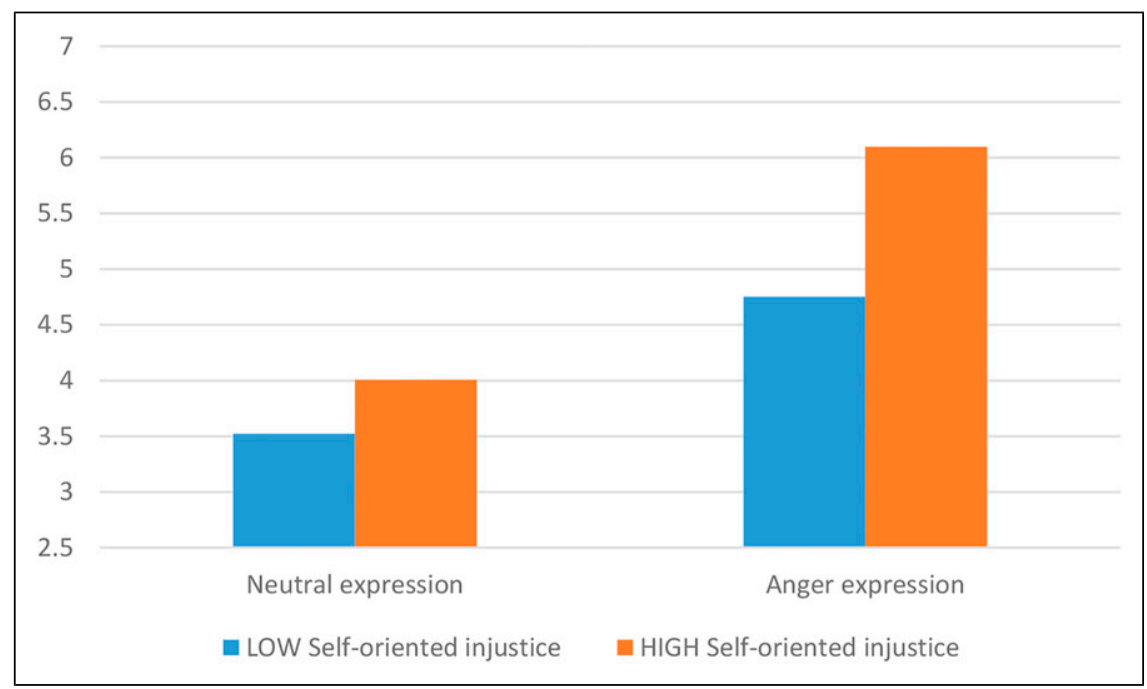

Figure 2. Interaction effect between level of anger expressiveness and maternal self-oriented injustice appraisal.

"It all seems so unfair") from the "blame and unfairness" subscale was included and adjusted to reflect maternal pain-related injustice appraisal in relation to their child's concurrent pain experience (i.e., "It is not fair that my child has to perform this painful cold pressor task.") and to the self (i.e., "It is not fair that I, as a parent, have to watch my child perform this painful cold pressor task"). Both items were rated prior to the mother's observation of their child performing the cold pressor task. Items were rated on an 11-point scale ranging from 0 ("Do not agree at all") to 10 ("Fully agree").

A 6-item state version of the Pain Catastrophizing Scale for Parents (PCS-P), ${ }^{33}$ Goubert et al., 2006) was used to assess maternal catastrophic thoughts in relation to the specific context of the cold pressor test. This state measure was developed and successfully used by
Goubert and colleagues ${ }^{33}$ and others ${ }^{28}$ and consists of two items for each subscale: rumination (e.g., "To what extent is it hard for you not to think about your child's pain?"), magnification (e.g., "To what degree do you think something serious may happen to your child during the task?"), and helplessness (e.g., "To what degree do you think you will not be able to stop your child's pain?"). Items were rated on an 11-point scale ranging from 0 ("Not at all") to 10 ("Very much"). Cronbach's alpha for the PCS-P state was 0.75 .

Maternal anger in response to their child performing the cold pressor task was assessed by means of a singleitem scale where mothers were asked to rate the extent to which they experienced anger while observing their child performing the CPT (i.e., "I felt anger"). The scale ranged from 0 ("Not at all") to 10 ("A lot"). 


\section{Mother-child interaction}

After CPT completion, a three-minute mother-child interaction was videotaped and transcribed verbatim allowing coding of maternal verbal pain-attending and non-pain-attending behavior in response to the child's participation in the CPT. The coding system used in the current study was an adaptation of the scheme developed by Walker and colleagues ${ }^{20}$ and has been successfully used in previous work with children and adolescents between 6 months and 15 years old. ${ }^{34}$

Maternal verbal behavior was coded using the following codes: (1) pain-attending behavior, (2) nonpain-attending behavior, and (3) other. Pain-attending behavior referred to the occurrence of any maternal utterance that focuses on the pain symptoms of the child or any aspect of the pain task (e.g., "Did it hurt a lot?"). Utterances not relating to any aspect of the pain task or the study context were coded as non-pain-attending ("What would you like to have for dinner tonight?"). Utterances relating to aspects of the study context other than the pain task were coded as other (e.g., "How was the computer task for you?"). The same codes were used to categorize the child's utterances. For each utterance, the behavior code was rated as occurring (coded 1) or not occurring (coded 0 ). Two independent coders each processed half of the transcripts, after which they completed the same procedure for $20 \%$ of each other's transcripts. Kappa reliability coefficients indicated a moderate inter-rater reliability for all coding categories $\left(k_{\text {pain-attending }}=0.59 ; k_{\text {non-pain-attending }}=0.46\right) .{ }^{35}$ Proportion scores for maternal pain-attending and nonpain-attending talk (i.e., divided by the total number of mother utterances) were computed and used within analyses.

\section{Procedure}

Mothers and children were invited to the faculty's laboratory space at Ghent University and received a formal introduction whereby they were informed that we were interested in maternal and child pain-related thoughts/feelings and how these may impact pain experience. Following consent, mother and child were directed to separate test rooms where they completed their respective self-report trait questionnaires, including demographic and pain-related information. Mothers then performed the pain and anger faces tasks in randomized order, to assess attentional bias toward child pain and adult anger stimuli. Next, both mother and child completed a series of state questionnaires measuring catastrophizing, child- and self-oriented injustice and anger. Subsequently, the child performed the CPT while their mother observed from an adjacent test room. After CPT completion, mother and child were reunited in the child's testing room and left alone for $3 \mathrm{~min}$, during which parent-child interactions were videotaped. At this time, participants were not aware of being videotaped so as to facilitate spontaneous behavior. The experimenter had merely left the room stating they would go check whether the previous phase of the study had been completed and registered successfully. Upon study completion, each dyad received a debriefing and was asked to sign an additional informed consent, indicating their agreement for the researchers to use their videos for analysis.

\section{Data analysis and eye movement parameters}

Eye movement parameters. Gaze behavior was analyzed using the Tobii software analysis package with the Clearview Fixation Filter, ${ }^{36}$ which determines the maximum pixel-distance between two points for them to be considered belonging to the same fixation and the minimum time for which gaze needs to be within the radius to be considered a fixation. In the current study, both target pictures were indicated as areas of interest, within which eye movements would be registered. A stable gaze within a 35-pixel radius that lasted at least $100 \mathrm{~ms}$ on a defined area of interest was registered as a visual fixation to that position. ${ }^{35}$ Based on these fixation criteria, two parameters were calculated for each picture, allowing examination of both initial orientation (i.e., probability of first fixation) and attentional maintenance (i.e., total fixation duration). Parameters were only calculated for participants of whom at least $70 \%$ of eye movements were registered successfully. ${ }^{26,28}$ One participant was removed from the dataset for this reason.

Probability of first fixation: The probability of first fixation indicates the occurrence of "initial orientation bias" which refers to the probability of the mother first fixating on the pain or anger face instead of the neutral face. This parameter was calculated by computing the proportion of trials where the first fixation was made in the pain or anger face over the total number of trials where the first fixation was made in either of the faces (i.e., pain/anger or neutral). A value of 0.50 was an indication of no bias, whereas a value greater or less than 0.50 indicated an initial orientation bias toward or away from pain or anger faces, respectively. This parameter was calculated for each level of facial pain expressiveness (LPE, MPE, and HPE) resulting in three indices of first fixation bias toward pain. One probability index was calculated for anger.

Attentional maintenance: An index for bias in attentional maintenance was calculated, indicating whether mothers spent more time attending to the pain or anger 
face compared to the neutral face across the trial. This parameter was calculated by subtracting the total fixation duration for neutral images from the total fixation duration for the corresponding pain image across each trial and then averaging the resulting scores for each of the pain and anger conditions. A positive value indicates a longer total time attending to the pain or anger face compared to the neutral face and is indicative of a maintained attention bias toward pain or anger cues. A negative value indicates a longer total time attending to the neutral over the pain or anger face, suggesting an attentional maintenance bias away from pain or anger cues. Indices were calculated for each level of pain expression (LPE, MPE, and HPE) resulting in three maintained attention bias indices for pain. One maintained attention bias index was calculated for anger.

Data analyses. Data-analysis was performed using the IBM SPSS Statistics software package for Windows (Version 24.0. Armonk, NY: IBM Corp). Hierarchical regression analyses were performed to examine the role of maternal child- and self-oriented injustice appraisal for maternal attentional biases for anger and maternal pain-attending and non-pain-attending behavior. For self-reported anger, no regression analysis was performed as only two participants gave a non-zero response (as described in the descriptives section; see 3.1). In each regression analysis, child age and sex (boys coded " 0 " and girls coded " 1 ") were entered in a first step. Considering the robust correlation between injustice appraisals and pain catastrophizing observed in previous studies as well as the current study ${ }^{4-6}$ (Sullivan et al., 2008; Miller et al., 2018; Baert et al., 2019; (see Table 1), maternal catastrophizing about child pain was entered in the second step, allowing us to examine the unique role of maternal injustice appraisals above and beyond that of catastrophizing. In a third step, maternal child- and self-oriented injustice was entered. Variance Inflation Factors were within the acceptable range (all VIF <1.7), indicating that multicollinearity was not an issue. Standardized betas are reported as an indicator of effect size.

A series of repeated measures ANCOVAs was performed to examine the role of maternal child- and selforiented injustice appraisals in attention to child pain (with either probability or gaze duration bias indices for LPE, MPE, and HPE within subject factors), picture ratings of pain (with NPE, LPE, MPE, and HPE as within subject factor), and anger intensity (with NAE vs. $\mathrm{AE}$ as a within-subject factor). Child sex (boys coded " 0 " and girls coded " 1 ") was entered as a between-subjects factor. Child age and maternal catastrophizing, and child- and self-oriented injustice were entered as covariates. Whenever the sphericity assumption was violated (Mauchly's test of sphericity was $p<0.05$ ), Greenhouse-Geisser corrections (with adjusted degrees of freedom, or NDf) were performed and reported. Partial eta-squared $\left(\eta_{p}{ }^{2}\right)$ are reported as an indicator of effect size. ${ }^{37}$

To examine interactions, the procedure described by Holmbeck (2002) was applied whereby continuous independent variables were first centered (i.e., parental catastrophizing and self-oriented and child-oriented injustice appraisals). Subsequently, significant interactions were examined by plotting and testing the significance of regression lines for high $(+1$ standard deviation above the mean) and low ( -1 standard deviation below the mean) values of the respective (i.e., moderator) variable.

\section{Results}

\section{Descriptive and correlation analysis}

Means, standard deviations and Pearson correlation coefficients between study measures are displayed in Table 1. For the state anger measure, descriptive analysis showed that only two mothers indicated a non-zero response. Therefore, this measure was not included in further analyses. Pearson correlation analyses showed that parental catastrophizing was significantly associated with both child-oriented $(r=$ $0.35, p<0.01)$ and self-oriented injustice appraisals $(r=0.55, p<0.05)$ and with maternal pain-attending talk $(r=0.51, p<0.01)$ indicating that higher levels of parental catastrophizing were associated with more child- and self-oriented injustice appraisals and more pain-attending talk. Further, higher parental selforiented injustice appraisals were associated with higher ratings of neutral $(r=0.46, p<0.01)$, low $(r=$ $0.47, p<0.01)$, moderate $(r=0.31, p<0.05)$, and high pain images $(r=0.30, p<0.05)$ displayed on child faces as well as with ratings of anger cues $(r=0.39, p<$ 0.01 ) displayed on adult faces.

To investigate the occurrence of absolute attention biases (i.e., probability of first fixation significantly different from 0.5 and attentional maintenance significantly different from 0 ) among the mothers, onesample t-tests were performed. For anger, results revealed no significant bias in probability of first fixation $(M=0.50, S D=0.06, t(39)=-0.238, p=0.81)$ or gaze duration $(M=-0.95, S D=28.01, t(39)=-0.213, p=$ $0.83)$ toward adult anger cues. For pain, results revealed a significant initial orientation bias (i.e., averaged across low, moderate, and high pain expression; $M=0.52, S D=0.05, t(40)=2.763, p=0.01)$ toward child pain faces, indicating that mothers showed a 


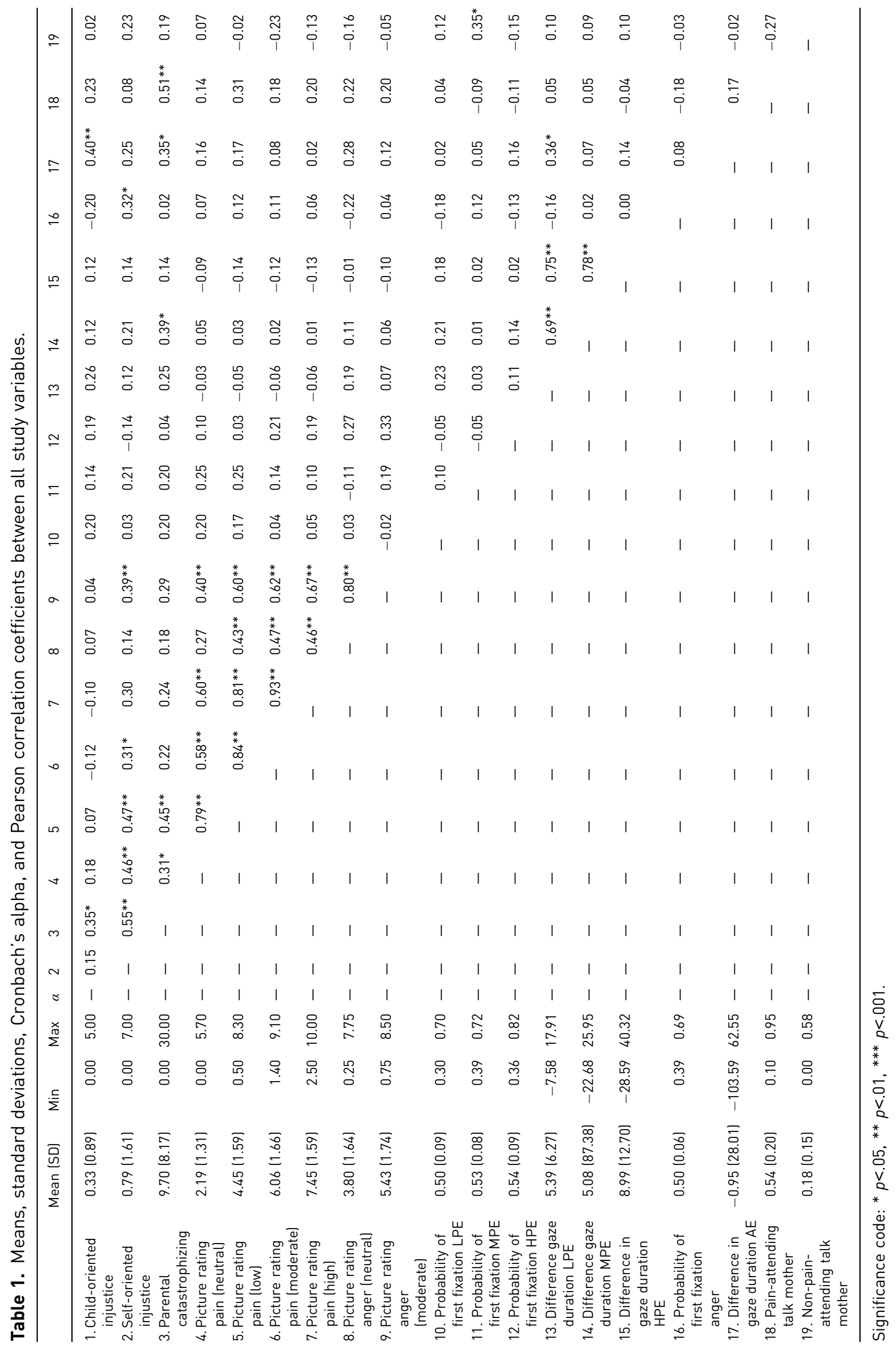


significantly higher likelihood of first focusing on the pain face rather than the neutral face. Results also showed a significant attentional maintenance bias toward child pain faces $(M=6.49, S D=8.05, t(40)=$ 5.16, $p=0.00$ ), indicating that mothers spent significantly more time attending to pain than neutral faces.

Repeated measures ANOVAs were performed to further explore the nature of initial and maintained attentional biases (i.e., whether these biases differed depending on levels of pain expressiveness) among mothers. Results revealed that there were no significant differences among first fixation bias toward low $(M=$ $0.49, S D=0.09)$, moderate $(M=0.53, S D=0.08)$, and high $(M=0.544, S D=0.09)$ pain expression $(F(2,80)=$ $\left.2.911, p=0.06, \eta_{p}{ }^{2}=0.07\right)$ displayed on child faces. For attentional maintenance, results showed a significant effect of facial pain expressiveness $(F(1.59,63.60)=$ $6.43, p=0.00, \eta_{p}^{2}=0.14$ ). Contrast analysis revealed that maternal attentional maintenance did not differ significantly between low $(M=5.39, S D=6.27)$ and moderate pain expressions $(M=5.08, S D=7.38, F(1,40)=0.13, p=$ $\left.0.73, \eta_{p}{ }^{2}=0.00\right)$. However, attentional maintenance was significantly longer for high pain expression $(M=8.44$, $S D=12.70)$ as compared to low $(F(1,40)=6.60, p=$ $\left.0.01, \eta_{p}{ }^{2}=0.14\right)$ and moderate pain $(F(1,40)=8.99, p=$ $\left.0.01, \eta_{p}^{2}=0.18\right)$ displayed on child faces.
The role of maternal injustice appraisals for maternal attention to child pain

Repeated measures ANCOVA with first fixation bias indices showed a significant main effect of child sex $\left(F(1,35)=5.074, p=0.03, \eta_{p}^{2}=0.13\right)$, but no other main effects (all $|F|<3.111$, ns). There were also no significant interaction effects for child sex, age, maternal catastrophizing, child-oriented or self-oriented injustice (all $|F|$ values $<0.948$, NS).

The analysis with gaze duration bias indices as outcome likewise revealed no significant main effects (all $|F|$ values $<3.856$, NS) or interaction effects (all $|F|$ values $<1.451$, NS).

\section{The role of maternal injustice appraisals for maternal attention to adult anger}

Analysis with maternal probability of first fixation upon adult anger as the outcome variable showed a significant effect of maternal self-oriented injustice $(\beta=0.49, p=0.018$; see Table 2$)$, suggesting that higher levels of self-oriented injustice were associated with a greater likelihood to first fixate upon anger displayed on adult faces. No other main or interaction effects were observed (all $|\beta|$ values $<0.21$, NS). For maternal gaze duration bias toward anger cues,

Table 2. Results for multiple hierarchical regression analysis.

\begin{tabular}{|c|c|c|c|c|c|c|c|c|}
\hline \multirow[b]{2}{*}{ Dependent } & \multirow[b]{2}{*}{ Step } & \multirow[b]{2}{*}{ Predictor } & \multirow{2}{*}{$\frac{\text { Parents }}{\beta}$} & \multirow[b]{2}{*}{ SE } & \multirow[b]{2}{*}{$t$} & \multirow[b]{2}{*}{$R^{2}$} & \multirow[b]{2}{*}{$R^{2}$ change } & \multirow[b]{2}{*}{$\Delta R^{2}$} \\
\hline & & & & & & & & \\
\hline \multirow[t]{5}{*}{ 1. Initial orientation anger } & \multirow[t]{2}{*}{1} & Child age & -0.17 & 0.01 & -1.04 & \multirow[t]{2}{*}{0.01} & \multirow[t]{2}{*}{0.01} & \multirow[t]{2}{*}{-0.04} \\
\hline & & Child sex & 0.01 & 0.02 & 0.03 & & & \\
\hline & 2 & Parental catastrophizing & -0.14 & 0.00 & -0.65 & 0.01 & 0.00 & -0.07 \\
\hline & \multirow[t]{2}{*}{3} & Child-oriented injustice & -0.21 & 0.01 & -1.25 & \multirow[t]{2}{*}{0.20} & \multirow[t]{2}{*}{0.19} & \multirow[t]{2}{*}{0.09} \\
\hline & & Self-oriented injustice & 0.49 & 0.01 & $2.48 *$ & & & \\
\hline \multirow[t]{5}{*}{ 2. Gaze duration anger } & \multirow[t]{2}{*}{1} & Child age & 0.19 & 2.13 & 1.18 & \multirow[t]{2}{*}{0.07} & \multirow[t]{2}{*}{0.07} & \multirow[t]{2}{*}{0.01} \\
\hline & & Child sex & -0.07 & 8.63 & -0.48 & & & \\
\hline & 2 & Parental catastrophizing & 0.10 & 0.74 & 0.50 & 0.15 & 0.08 & 0.07 \\
\hline & \multirow[t]{2}{*}{3} & Child-oriented injustice & 0.36 & 5.04 & $2.20 *$ & \multirow[t]{2}{*}{0.25} & \multirow[t]{2}{*}{0.11} & \multirow[t]{2}{*}{0.14} \\
\hline & & Self-oriented injustice & 0.06 & 3.23 & 0.30 & & & \\
\hline \multirow[t]{5}{*}{ 3. Pain-attending behavior } & \multirow[t]{2}{*}{1} & Child age & -0.03 & 0.02 & -0.19 & \multirow[t]{2}{*}{0.08} & \multirow[t]{2}{*}{0.03} & \multirow[t]{2}{*}{0.03} \\
\hline & & Child sex & 0.21 & 0.06 & 1.46 & & & \\
\hline & 2 & Parental catastrophizing & 0.63 & 0.00 & $3.51 * *$ & 0.34 & 0.26 & 0.28 \\
\hline & \multirow[t]{2}{*}{3} & Child-oriented injustice & 0.03 & 0.03 & 0.21 & \multirow[t]{2}{*}{0.36} & 0.03 & 0.27 \\
\hline & & Self-oriented injustice & -0.20 & 0.02 & -1.14 & & & \\
\hline 4. Non-pain-attending behavior & 1 & Child age & -0.11 & 0.01 & -0.60 & 0.00 & 0.00 & -0.05 \\
\hline & & Child sex & -0.03 & 0.05 & -0.15 & & & \\
\hline & 2 & Parental catastrophizing & 0.14 & 0.00 & 0.63 & 0.04 & 0.04 & -0.04 \\
\hline & 3 & Child-oriented injustice & -0.06 & 0.03 & -0.31 & 0.07 & 0.03 & -0.07 \\
\hline & & Self-oriented injustice & 0.20 & 0.02 & 0.95 & & & \\
\hline
\end{tabular}

Significance code: ${ }^{*} p<0.05,{ }^{* *} p<0.01,{ }^{* * *} p<0.001$. 
analysis revealed a significant effect of maternal childoriented injustice $(\beta=0.36, p=0.035)$, suggesting that higher levels of maternal child-oriented injustice were associated with enhanced maintained attention toward adult anger cues. No other significant main or interaction effects were observed (all $|\beta|$ values $<0.30$, NS).

\section{The role of maternal injustice appraisals for maternal ratings of child pain and adult anger stimuli}

Repeated measures ANCOVA with maternal ratings of child pain images revealed a main effect of level of pain expressiveness $\left(F(3,111)=8.085, p=0.001, \eta_{p}{ }^{2}=\right.$ 0.18 ), indicating that pain intensity was rated higher with increasing levels of pain expression. Contrast analyses indicated significantly higher pain ratings for high versus moderate pain expressions $(F(1,37)=$ 13.448, $p=0.001, \eta_{p}^{2}=0.27$ ) but no differences for neutral versus low $\left(F(1,37)=2.073, p=0.158, \eta_{p}{ }^{2}=\right.$ $0.05)$ or low versus moderate $(F(1,37)=2.128, p=$ $0.153, \eta_{p}^{2}=0.05$ ). No other main effects (all $|F|$ values $<1.787$, NS) or interaction effects (all $|F|$ values $<3.207$, NS) were observed.

Analyses with maternal ratings of adult anger images revealed no significant main effects (all $|F|$ values $<3.897$, NS). However, there was a significant interaction effect of parental self-oriented injustice appraisal $\left(F(1,36)=6.139, p=0.018, \eta_{p}{ }^{2}=0.15\right)$, indicating that level of anger expression (i.e., neutral vs. angry) affected ratings of anger differently for parents with high versus low levels of self-oriented injustice (Figure 2). Separate ANOVAs for parents with low and high levels of self-oriented injustice indicated that adult anger faces were rated as significantly more angry than adult neutral faces for both groups. Yet, the effect was substantially larger for parents reporting high levels of self-oriented injustice $(+1 \mathrm{SD}$ above the mean; $F(1,40)=120.232$, $\left.p=0.00, \eta_{p}^{2}=0.75\right)$ compared to parents reporting low levels of self-oriented injustice $(-1 \mathrm{SD}$ below the mean; $\left.F(1,40)=12.939, p=0.001, \eta_{p}^{2}=0.24\right)$, suggesting that angry faces are perceived to be much more angry when self-oriented injustice is high. Indeed, additional and separate analyses for the neutral and angry image sets indicated that angry faces were rated as significantly more angry amongst parents who reported high levels of self-oriented injustice compared to parents who reported low levels of selforiented injustice $(F(1)=7.431, p<0.01)$. No such effect was observed within the neutral image set $(F(1)=0.785, \mathrm{NS})$.

\section{The role of maternal injustice appraisals for maternal pain-attending and non-pain-attending behavior}

Analyses with parental pain-attending talk as the dependent variable only showed a significant effect of parental catastrophizing about child pain $(\beta=0.626$, $p=0.001$; see Table 2), indicating that higher levels of parental catastrophizing were associated with more parental pain-attending behavior. No other significant main or interaction effects were found (all $|\beta|$ values $<0.197$, NS). No significant effects were observed for parental non-pain attending behaviors (all $|\beta|$ values $<0.199$, NS).

\section{Discussion}

The present study investigated the role of maternal child- and self-oriented injustice appraisals in explaining attentional processing of child pain and selfrelevant adult anger cues. We also investigated how these injustice appraisals affect maternal pain-attending behavior in response to their child's experimental pain experience (i.e., cold pressor pain). We hypothesized that higher levels of maternal state injustice appraisals would be uniquely associated (i.e., independent from parental catastrophizing) with greater attentional bias to child pain and adult anger cues, and with more parental pain-attending behaviors. Throughout analyses we explored the potentially differential impact of maternal child- versus self-oriented injustice appraisals as well as the role of varying levels of pain expressiveness with respect to attentional bias to child pain and associations with both indices of attentional bias (i.e., probability of first fixation and attentional maintenance). Results indicated that neither maternal child- nor self-oriented injustice appraisals contributed to attention bias indices to pain or ratings of child pain intensity; likewise, maternal catastrophizing about child pain was not a significant predictor of these outcomes. With respect to attention toward self-relevant anger cues, findings indicated that maternal child- and self-oriented injustice appraisals were differentially associated with both indices of attentional bias. Specifically, in terms of initial orientation, mothers who reported higher levels of selforiented injustice appraisals showed a greater probability of first fixating upon anger cues. In terms of attentional maintenance, mothers who reported higher levels of child-oriented injustice showed greater attentional maintenance toward anger cues. Further, maternal ratings of anger cues became increasingly pronounced for mothers reporting high self-oriented injustice appraisals compared to mothers reporting low self-oriented 
injustice appraisals. Finally, maternal child- and selforiented injustice appraisals did not contribute to maternal pain-attending behavior following their child's CPT-induced pain experience. Maternal pain-attending behavior was only associated with maternal catastrophizing about child pain, indicating that higher levels of maternal catastrophizing about child pain contributed to more pain-attending behaviors.

The present findings contribute to the literature in a number of ways. In particular, to the best of our knowledge, this is the first study to examine associations between parental injustice appraisals (about child pain) and parental anger. While previous work highlights the role of anger in perceived injustice relating to personal pain, ${ }^{7,11,12,38,39}$ the current study extended such findings to an interpersonal context. ${ }^{40}$ Examining how injustice appraisals relate to attention toward anger was based on earlier work in the context of experimental pain, suggesting that attentional bias to anger cues may be of greater importance than attentional bias to pain. ${ }^{12}$ Our findings support this notion. Instead of impacting attentional processing of child pain stimuli (i.e., other relevant cues), maternal injustice appraisals biased attention toward self-relevant anger cues on the faces of fellow adults. Interestingly though, maternal selforiented and child-oriented injustice appraisals were differentially associated with biases in initial orientation and attentional maintenance; that is, whereas selforiented appraisals contributed to enhanced initial attention to anger (adult faces), child-oriented appraisals contributed to enhanced attentional maintenance to anger. These findings support the proposed distinction between parental self- versus child-oriented appraisals about child pain and coincide with an affectivemotivational account on interpersonal dynamics in pain ${ }^{40}$ which explicitly distinguishes self-oriented appraisals from other-oriented appraisals and posits that they have differential effects. Specifically, self-oriented appraisals, whereby stimuli (e.g., child pain) are appraised with relevance to one's own goals, are thought to lead to self-oriented emotional responses that prioritize behavior that is less attuned to another's needs but more oriented toward one's own needs. Conversely, other-oriented appraisals are thought to give rise to other-oriented emotions that may promote behavior that is more responsive and attuned to the needs of another.

While it remains to be known how observed differential attentional patterns - as a function of maternal self- versus child-oriented injustice appraisalstranslate into diverse caregiving behavior patterns, the literature suggests that initial and maintained attentional allocation represent partially independent processes that may be driven by different mechanisms and have different consequences. Early attentional deployment has been found to be more associated with bottom-up processes such as stimulus detection (e.g., threat), ${ }^{41-43}$ whereas later attentional maintenance has been found to be associated with more elaborative and conscious information processing. Differential attentional patterns may show differential relationships with threat reappraisal and emotion regulation and thus potentially also lead to differential caregiving responses. ${ }^{13,44,45}$ Previous research on parental child- versus self-oriented injustice appraisals also found differential effects on various domains of child (pain-related) functioning. Specifically, we previously observed that only parental selforiented injustice had a negative impact amongst a comparable sample of school children; child-oriented appraisals did not affect child outcomes. However, future research is warranted to replicate the observed differential associations of child- versus self-oriented injustice appraisals with attentional processing of anger, their role in understanding diverse caregiving responses, and their impact on child (pain-related) functioning.

The current study demonstrated no association of injustice appraisals with pain attending behavior following the pain induction task. Maternal pain attending behavior was only impacted by maternal catastrophizing about child pain. Previous work has also found a link between higher parental catastrophizing and caregiving, specifically, with more solicitous and restrictive caregiving responses which are, in turn, associated with worse child functioning. ${ }^{14,16,19,34}$ Yet, despite high correlations between perceived injustice and catastrophizing in previous work ${ }^{6,21}$ and in the current study, our findings highlight the conceptual distinctiveness of these constructs and suggest that they have differential behavioral routes to impact child outcomes. Previous work on parental illness appraisals suggests that child functioning may be affected through impaired parental adjustment. ${ }^{46,47}$ As proposed in the Model of Distress Transmission, ${ }^{48,49}$ parental perceptions of injustice and associated emotional distress (e.g., anger) may exhaust the parental capacity for sustained and effective caregiving. ${ }^{50,51}$ Further, depending on how parents regulate experienced anger, this may translate into parental caregiving behavior that is characterized by negative facial expressions, less warmth, sensitivity, and affection, and more hostility and disengagement. ${ }^{48,49,51,52}$ Future research may also benefit from assessing the source of the perceived injustice and the recipient of parental anger as determinants of the impact of parental injustice appraisals on child well-being. Even though parental anger may not be originally oriented toward the child, it may still exert 
an impact, for example, through the process of anger deflection. ${ }^{53,54}$

A number of study limitations and directions for future research should be taken into consideration. A first issue pertains to the size and composition of the sample. Due to the small sample size, we were only powered to identify large effects. Further, the sample consisted of Belgian mothers and had limited racial, ethnic and gender diversity. Earlier work suggests that mothers and fathers may perceive and respond to their child's pain in different ways, ${ }^{55-57}$ highlighting the need to also include fathers in this line of work. As such, further research in larger and more diverse samples is warranted. Second, the current study was conducted in an artificial lab-based environment and involved healthy children and their mothers, which may warrant caution in interpreting the clinical implications of the current findings. It is plausible that in pediatric chronic pain samples, these associations may be more pronounced or even differ from those observed in an artificial laboratory setting with experimentally induced pain. Third, different aspects of the observational setting may have limited the current paradigm's face validity and ability to induce strong perceptions of injustice. For instance, the lab-based design of a voluntary participation in the study may partially account for the low scores on measures of mothers' catastrophizing, injustice, and anger, resulting in limited variability in the data. While the current lab-based research paradigm has extensively been used to elucidate the role of parental appraisals about child pain, primarily catastrophic appraisals about child pain future work may benefit from increasing the salience of parental-pain related appraisals, including injustice appraisals, for instance, by means of experimental manipulations. ${ }^{12}$

Despite these limitations, this study provides a first step in exploring the construct of parental child- and selforiented injustice appraisals in response to child pain and the mechanisms underlying these relationships. It entails the first examination of attentional bias in relation to injustice appraisals in mothers of children experiencing (acute) pain and the first examination of the relationship between parental injustice appraisals and pain-attending behavior toward their child's pain. The clinical relevance of the current findings is evident in that it provides insight in the emotional correlates of perceived injustice and may inform interventions aimed at strengthening emotion regulation in parents of children suffering from chronic pain.

\section{Acknowledgments}

The authors wish to thank Charlotte Horemans, Astrid Vandenabeele, Lotte Geeroms, and Sophie Vandenbroucke for their contribution to the data collection and preparation of this study.

\section{Declaration of conflicting interests}

The author(s) declared no potential conflicts of interest with respect to the research, authorship, and/or publication of this article.

\section{Funding}

The author(s) disclosed receipt of the following financial support for the research, authorship, and/or publication of this article: The current study was funded by a BOF Research grant, obtained by Prof. Dr. Tine Vervoort.

\section{ORCID iDs}

Fleur Baert (1) https://orcid.org/0000-0002-7602-5859

Megan M Miller (1) https://orcid.org/0000-0002-6222-2659

\section{Ethical approval}

Ethical approval for this study was obtained from the ethical committee of the Faculty of Psychology and Educational Sciences at Ghent University (approval number "2017/45/ Tine Vervoort").

\section{Informed consent}

Written informed consent was obtained from all subjects (parent and child) before the study.

\section{References}

1. Palermo TM, Schwartz L, Drotar D, et al. Parental report of health-related quality of life in children with sickle cell disease. F Behav Med 2002, 25(3), 269-283.

2. Palermo TM and Chambers CT. Parent and family factors in pediatric chronic pain and disability: An integrative approach. Pain 2005, 119(3), 1-4.

3. Hadjistavropoulos et al. A biopsychosocial formulation of pain communication. Psych Bull 2011, 137(6), 910.

4. Miller MM, Wuest D, Williams AE, et al. Injustice perceptions about pain: parent-child discordance is associated with worse functional outcomes. Pain 2018 159(6), 1083-1089.

5. Baert F, Miller MM, Trost Z, et al. Parental injustice appraisals in the context of child pain: Examining the construct and criterion validity of the IEQ-Pc and IEQPs. I Pain 2019, 21(1),195-211.

6. Sullivan MJL, et al. The role of perceived injustice in the experience of chronic pain and disability: scale development and validation. f Occup Rehab 2008, 18, 249-261.

7. Trost Z, Vangronsveld K, Linton SJ, et al. Cognitive dimensions of anger in chronic pain. Pain 2012, 153(3), 515-517. 
8. Greenwood KA, Thurston R, Rumble M, et al. Anger and persistent pain: current status and future directions. Pain 2003, 103(1-2), 1-5.

9. Sturgeon JA, Carriere JS, Kao M-CJ, et al. Social disruption mediates the relationship between perceived injustice and anger in chronic pain: A collaborative Health Outcomes Information Registry study. Ann Behav Med 2016, 50(6), 802-812.

10. Carriere JS, Sturgeon JA, Yakobov E, et al. The impact of perceived injustice on pain-related outcomes: A combined model examining the mediating roles of pain acceptance and anger in a chronic pain sample. Clin $\mathcal{F}$ Pain 2018, 34(8), 739-747.

11. Scott W, Trost Z, Bernier E, et al. Anger differentially mediates the relationship between perceived injustice and chronic pain outcomes. Pain 2013, 154(9), 1691-1698.

12. Trost Z, Van Ryckeghem D, Scott W, et al. The effect of perceived injustice on appraisals of physical activity: an examination of the mediating role of attention bias to pain in a chronic low back pain sample. 7 Pain 2016, 17(11), 1207-1216.

13. Liossi C, Schoth DE, Bradley BP, et al. Time course of attentional bias for pain related cues in chronic daily headache sufferers. Eur F Pain 2009, 13, 963-969.

14. Langer SL, Romano JM, Levy RL, et al. Catastrophizing and parental response to child symptom complaints. $\mathcal{F}$ Child Health Care 2009, 38(3), 169-184.

15. Sullivan MJ, Davidson N, Garfinkel B, et al. Perceived injustice is associated with heightened pain behavior and disability in individuals with whiplash injuries. Psychol Injury L 2009, 2(3-4), 238-247.

16. Caes L, Vervoort T, Eccleston C, et al. Parental catastrophizing about child's pain and its relationship with activity restriction: the mediating role of parental distress. Pain 2011, 152(1), 212-222.

17. Goubert L, Vervoort T, De Ruddere L, et al. (2012). The impact of parental gender, catastrophizing and situational threat upon parental behaviour to child pain: A vignette study. Eur F Pain 2012, 16(8), 1176-1184.

18. Lynch-Jordan AM, Kashikar-Zuck S, Szabova A, et al. The interplay of parent and adolescent catastrophizing and its impact on adolescents' pain, functioning and pain behavior. Clin F Pain 2013, 29(8), 681-688.

19. Caes L, Vervoort T, Devos P, et al. Parental distress and catastrophic thoughts about child pain: Implications for parental protective behavior in the context of child leukemia related medical procedures. Clin 7 Pain 2014, 30(9), 787-799.

20. Walker LS, Williams SE, Smith CA, et al. Parent attention versus distraction: Impact on symptom complaints by children with and without chronic functional abdominal pain. Pain 2006, 122(1-2), 43-52.
21. Sullivan MJL, Adams H, Martel M-O, et al. Catastrophizing and perceived injustice: Risk factors for the transition to chronicity after whiplash injury. Spine 2011, 36(25), 244-249.

22. Sullivan MJ, Scott W and Trost Z. (2012). Perceived injustice: a risk factor for problematic pain outcomes. Clin $\mathcal{F}$ Pain 2012, 28(6), 484-488.

23. Von Baeyer CL, Piira T, Chambers CT, et al. Guidelines for the Cold Pressor Task as an Experimental Pain Stimulus for Use With Children. $f$ Pain 2005, 6(4), 218-227.

24. Birnie KA, Petter M, Boerner KE, et al. Contemporary use of the cold pressor task in pediatric pain research: A systematic review of methods. F Pain 2012, 13, 817-826.

25. Vervoort T, Goubert L and Crombez G. The relationship between high catastrophizing children's facial display of pain and parental judgment of their child's pain. Pain 2009, 142(1-2), 142-148.

26. Vervoort T, Trost $Z$ and Van Ryckeghem DM. Children's selective attention to pain and avoidance behaviour: the role of child and parental catastrophizing about pain. Pain 2013b, 154(10), 1979-1988.

27. Vervoort T, Trost Z, Sütterlin S, et al. (2014). Emotion regulatory function of parent attention to child pain and associated implications for parental pain control behaviour. Pain 2014, 155, 1453-1463.

28. Heathcote LC, Lau JY, Mueller SC, et al. Child attention to pain and pain tolerance are dependent upon anxiety and attention control: An eye-tracking study. Eur f Pain 2017, 21(2), 250-263.

29. Chambers CT, McGrath PJ, Gilbert CA, et al, 1996. Child Facial Coding System - Revised Manual. IWK-Grace Health Centre, Dalhousie University \& University of British Columbia, Halifax, NS, Canada.

30. Vervoort T, Caes L, Crombez G, et al. Parental catastrophizing about children's pain and selective attention to varying levels of facial expression of pain in children: A dot-probe study. Pain 2011, 152, 1751-1757.

31. Ekman P and Friesen W. Investigator's Guide to the Facial Action Coding System. Palo Alto, CA: Consulting Psychologists Press, 1978.

32. Goubert L, Vervoort T, Sullivan MJL, et al. Parental emotional responses to their child's pain: The role of dispositional empathy and catastrophizing about their child's pain. F Pain 2008, 9(3), 272-279.

33. Goubert L, Eccleston C, Vervoort T, et al. Parental catastrophizing about their child's pain. The parent version of the Pain Catastrophizing Scale (PCS-P): a preliminary validation. Pain 2006, 123(3), 254-263.

34. Caes L, Vervoort $\mathrm{T}$, Trost $\mathrm{Z}$, et al. Impact of parental catastrophizing and contextual threat on parents' emotional and behavioral responses to their child's pain. Pain 2012, 153(3), 687-695. 
35. Yang Z, Jackson T, Gao X, et al. (2012). Identifying selective visual attention biases related to fear of pain by tracking eye movements within a dot-probe paradigm. Pain 2012, 153, 1742-1748.

36. Salvucci DD and Goldberg JH. (2000). Identifying fixations and saccades in eyetracking protocols. In Proceedings of the 2000 symposium on eye tracking research $\mathcal{E}$ applications, p 71-78, ACM, NY, USA.

37. Lakens D. Calculating and reporting effect sizes to facilitate cumulative science: A practical primer for t-tests and ANOVAs. Front Psychol 2013, 4, 863.

38. Barclay LJ, Skarlicki DP and Pugh SD. Exploring the Role of Emotions in Injustice Perceptions and Retaliation. F Appl Psychol 2005, 90(4), 629-643.

39. Orth U, Montada L and Maercker A. Feelings of revenge, retaliation motive and post-traumatic stress reactions in crime victims. F Interpers Violence 2006, 21, 229-243.

40. Vervoort T and Trost Z. (2017). Examining affectivemotivational dynamics and behavioral implications within the interpersonal context of pain. 7 Pain 2017, 18(10), 1174-1183.

41. Robinson MD. Running from William James' Bear: A review of preattentive mechanisms and their contributions to emotional experience. Cogn Emot 1998, 12, 667-696.

42. Van Doorn J, Zeelenberg $M$ and Breugelmans SM. Emotional experience and prosocial behavior in observers of unjust situations. Appl Psychol Crim fustice 2019, 15(1), 41-59.

43. Van Damme S, Crombez G and Eccleston C. Retarded disengagement from pain cues: the effects of pain catastrophizing and pain expectancy. Pain 2002, 100(1-2), 111-118.

44. Cisler JM and Koster EHW. Mechanisms of attentional biases toward threat in anxiety disorders: An integrative review. Clin Psychol Rev 2010, 30, 203-216.

45. Vervoort T, Trost Z, Prkachin KM, et al. Attentional processing of other's facial display of pain: an eye tracking study. Pain 2013, 154(6), 836-844.

46. Ryan JL, Mullins LL, Ramsey RR, et al. Caregiver demand and parent distress in juvenile rheumatic disease: the mediating effect of parent attitude toward illness. $\mathcal{F}$ Clin Psychol Med Settings 2013, 20(3), 351-360.

47. Mullins LL, Cushing CC, Suorsa KI, et al. Parent illness appraisals, parent adjustment and parent-reported child quality of life in pediatric cancer. Ped Hematol Oncol 2016, 33(5), 314-326.

48. Downey G, Purdie V and Schaffer-Neitz R. Anger transmission from mother to child: A comparison of mothers in chronic pain and well mothers. $\mathcal{F}$ Marriage Fam 1999, 61(1), 62-73.

49. Downey G and Coyne JC. Children of depressed parents: An integrative Review. Psychol Bull 1990, 108, 50-76.

50. Dix T. The affective organization of parenting: Adaptive and maladaptive processes. Psychol Bull 1991, 110, 3-25.

51. Lovejoy MC, Graczyk PA, O’Hare E, et al. Maternal depression and parenting behavior: A meta-analytic review. Clin Psychol Rev 2000, 20, 561-592.

52. Field A. (2013). Discovering Statistics with IBM SPSS Statistics. Newbury Park, CA: Sage.

53. Fernandez E and Turk DC. The scope and significance of anger in the experience of chronic pain. Pain 1995, 61, 165-175.

54. Fernandez E and Wasan A. The anger of pain sufferers: Attributions to agents and appraisals of wrongdoings. In Potegal M., Stemmler G. and Spielberger C. (Eds.), International handbook of anger: Constituent and concomitant biological, psychological, and social processes 2009; 449-464. Springer Science + Business Media.

55. Yang Z, Jackson $\mathrm{T}$, Gao X, et al. Identifying selective visual attention biases related to fear of pain by tracking eye movements within a dot-probe paradigm. Pain 2012, 153, 1742-1748.

56. Zeman J and Garber J. Display rules for anger, sadness and pain: It depends on who is watching. Child Dev 1996, 67(3), 957-973.

57. Hechler T, Vervoort T, Hamann $M$, et al. Parental catastrophizing about their child's chronic pain: Are mothers and fathers different? Eur f Pain 2011, 15(5), $515 \mathrm{e} 1-515 \mathrm{e} 9$. 